\title{
Eye spectral sensitivity in fresh- and brackish-water populations of three glacial-relict Mysis species (Crustacea): physiology and genetics of differential tuning
}

\author{
Kristian Donner ${ }^{1} \cdot$ Pavel Zak $^{2} \cdot$ Martta Viljanen $^{1} \cdot$ Magnus Lindström $^{3}$. \\ Tatiana Feldman $^{2,4} \cdot$ Mikhail Ostrovsky ${ }^{2,4}$
}

Received: 7 August 2015 / Revised: 26 February 2016 / Accepted: 29 February 2016 / Published online: 16 March 2016

(C) The Author(s) 2016. This article is published with open access at Springerlink.com

\begin{abstract}
Absorbance spectra of single rhabdoms were studied by microspectrophotometry (MSP) and spectral sensitivities of whole eyes by electroretinography (ERG) in three glacial-relict species of opossum shrimps (Mysis). Among eight populations from Fennoscandian fresh-water lakes $(L)$ and seven populations from the brackish-water Baltic Sea $(S), L$ spectra were systematically red-shifted by 20-30 nm compared with $S$ spectra, save for one $L$ and one $S$ population. The difference holds across species and bears no consistent adaptive relation to the current light environments. In the most extensively studied $L-S$ pair, two populations of M. relicta $\left(L_{\mathrm{p}}\right.$ and $\left.S_{\mathrm{p}}\right)$ separated for less than 10,000 years, no differences translating into amino acid substitutions have been found in the opsin genes, and the chromophore of the visual pigments as analyzed by HPLC is pure A1. However, MSP experiments with spectrally selective bleaching show the presence of two rhodopsins $\left(\lambda_{\max } \approx 525-530 \mathrm{~nm}\right.$, MWS, and $565-570 \mathrm{~nm}$, LWS) expressed in different proportions. ERG recordings of responses to "red" and "blue" light linearly polarized at orthogonal angles indicate segregation of the pigments into different cells differing in polarization sensitivity. We propose that the pattern of development of LWS and MWS photoreceptors is governed by an ontogenetic
\end{abstract}

Kristian Donner

kristian.donner@helsinki.fi

1 Department of Biosciences, University of Helsinki, P.O.Box 65 (Viikinkaari 1), 00014 Helsinki, Finland

2 Emanuel Institute of Biochemical Physics, Russian Academy of Sciences, Moscow, Russia

3 Tvärminne Zoological Station, University of Helsinki, Hanko, Finland

4 Department of Molecular Physiology, Biological Faculty, Lomonosov Moscow State University, Moscow, Russia switch responsive to some environmental signal(s) other than light that generally differ(s) between lakes and sea, and that this reaction norm is conserved from a common ancestor of all three species.

Keywords Vision · Rhodopsin · Phenotypic plasticity · Evolutionary adaptation $\cdot$ Compound eye $\cdot$ Polarization sensitivity
Abbreviations
A1 Retinal
A2 3,4-Didehydroretinal
ERG Electroretinography
GFRKD Standard visual pigment template of Govardovs- kii et al. (2000)
HPLC High performance liquid chromatography
MSP Microspectrophotometry
MWS Middle wavelength sensitive
$L \quad$ Lake
$L_{\mathrm{p}} \quad$ M. relicta population of Lake Pääjärvi
LWS Long wavelength sensitive
$S \quad$ Sea
$S_{\mathrm{p}} \quad$ M. relicta population of Pojoviken Bay of the Baltic Sea
SNR Signal-to-noise ratio
QC Quantum catch
WMTL Wavelength of maximal transmission of light
$\lambda_{\max } \quad$ Wavelength of maximal absorbance/sensitivity

\section{Introduction}

The genus Mysis (opossum shrimps) comprises a great number of species widely distributed over the arctic and temperate zones of the northern hemisphere. Among these 
are four glacial-relict sibling species inhabiting fresh and brackish waters, three in northern Europe (M. relicta, $M$. salemaai and M. segerstralei) and one in North America (M. diluviana) (Väinölä et al. 1994). Molecular evidence indicates that the evolutionary radiation of this group (formerly regarded as a single species $M$. relicta, sensu lato) dates back $\geq 2 \mathrm{Myr}$, although the divergence of $M$. segerstralei and M. salemaai is more recent (Väinölä 1986; Audzijonyte et al. 2005; Audzijonyte and Väinölä 2005, 2006). This as well as the relation of the whole group to the wider genus Mysis is schematically shown in Fig. 1a (cf. Audzijonyte et al. 2012). The "glacial-relict" branch of the primarily marine genus Mysis is so called because isolation patterns and speciation in northern coastal seas and lakes have been inextricably linked to Pleistocene glaciation history. The Fennoscandian populations have experienced repeated switches between marine, brackish/ coastal/estuarine and freshwater conditions throughout the Pleistocene, up until their comparatively recent $(<10 \mathrm{kyr}$, Eronen et al. 2001) postglacial isolation in inland lakes and the brackish-water Baltic Sea. Most likely, these switches have often been associated with significant changes in light conditions.

Concurrently, their vision has undergone apparently rapid changes in spectral sensitivity. The first report of what looked like ultra-fast evolutionary adaptation to different light conditions in $M$. relicta came from two populations living in different environments in southern Finland: the greenish coastal Pojoviken Bay and the dark brown Lake Pääjärvi (Lindström and Nilsson 1988; locations \#11 and $\# 10$ in Fig. 1b). These populations will be denoted $S_{\mathrm{p}}$ ("Sea, Pojoviken") and $L_{\mathrm{p}}$ ("Lake, Pääjärvi”). The ERG sensitivity spectrum of the $L_{\mathrm{p}}$ eye was found to be red-shifted by ca $30 \mathrm{~nm}$ compared with that of the $S_{\mathrm{p}}$ eye. This appeared to be clearly "adaptive" in a habitat where peak light transmission is at $680 \mathrm{~nm}$ and $99 \%$ of all light is restricted to wavelengths $>550 \mathrm{~nm}$ even a few meters below the surface (Lindström 2000; cf. Figs. 2, 7 of the present study). As the phylogenies, paleogeography and current habitats of mysid species and populations were more extensively mapped (Audzijonyte et al. 2005; Audzijonyte and Väinölä 2005), it became evident what a rich and unique model system they offer for studying changes in the spectral properties of vision (adaptive or not) on very different time scales.

Surprisingly, a similar 20-30 nm red shift of vision in fresh-water ("lake", $L$ ) populations compared with brackish-water ("sea", $S$ ) populations was found across all three European glacial-relict Mysis species, overriding $\geq 2 \mathrm{Myr}$ of separate evolution and opsin gene divergence (Audzijonyte et al. 2012). The present article offers a review and reappraisal of results from more than a decade in the light of a large body of new data. Jokela-Määttä et al. (2005) concluded that the European glacial-relict Mysis species possess a single A2 visual pigment and that spectral differences must be due to differences in the (single) opsin. We now propose that all express two A1 visual pigments in different proportions under the control of an essentially bistable developmental switch responding to some environmental signal(s) that generally differ(s) between fresh and salt/ brackish water. We hypothesize that such a genetic reaction norm (Woltereck 1909, 1928) conserved from a common ancestor underlies the dominant bimodal $L-S$ distribution of spectral sensitivities across species, while evolutionary divergence of the opsins between species contributes comparatively minor variation components.

\section{Materials and methods}

\section{Animals}

Figure 1a shows the phylogenetic position within the genus Mysis of the three glacial-relict species M. relicta, M. salemaai and M. segerstralei chiefly considered in the present work. We include data on seven brackish-water $(S)$ and eight fresh-water $(L)$ populations from 14 locations as shown on the map in Fig. 1b. In addition, we have included three populations of M. mixta (from locations \#12-14) belonging to the marine-Caspian clade.

The data on populations from locations \#1-6 are from earlier studies by Jokela-Määttä et al. (2005) and Audzijonyte et al. (2012). For the new experiments, mysids were captured at locations \#7-14 between October 2013 and August 2014 by horizontal netting from the top of the sediment (population \#11) or by vertical net from the entire water column (all the others). After capture, the animals were transferred in light-tight cooler boxes to aquaria, where they were kept in darkness at $+7{ }^{\circ} \mathrm{C}$. When studying samples from locations where several mysid species coexist, we determined the species of each specimen morphologically (by microscopic inspection) and/or molecularly after the experiment (Väinölä et al. 2002; Audzijonyte and Väinölä 2005).

\section{Microspectrophotometry (MSP)}

The animals were transferred under dim red light from aquaria, where they had been kept in darkness, to a lighttight container at least 1 day before experiments to allow for proper dark-adaptation. After that, all procedures and preparations were performed under infrared light with the aid of an IR-viewer. Absorbance spectra were recorded from single rhabdoms with lateral incidence of light polarized perpendicularly to the long axis of the rhabdom. For detailed descriptions of recording and analysis, see JokelaMäättä et al. (2005). It should be noted that our MSP does 
Fig. 1 a Phylogeny of the glacial-relict Mysis species and their relation to other Mysis species flocks, based on multilocus sequence data and morphology (after Audzijonyte et al. 2005). Besides the glacial-relict species $M$. relicta, $M$. salemaai and $M$. segerstralei, the present study includes the species $M$. mixta as an outgroup representing the marine/Caspian clade. b Geographic locations of the populations included in the present study (see Table 1)

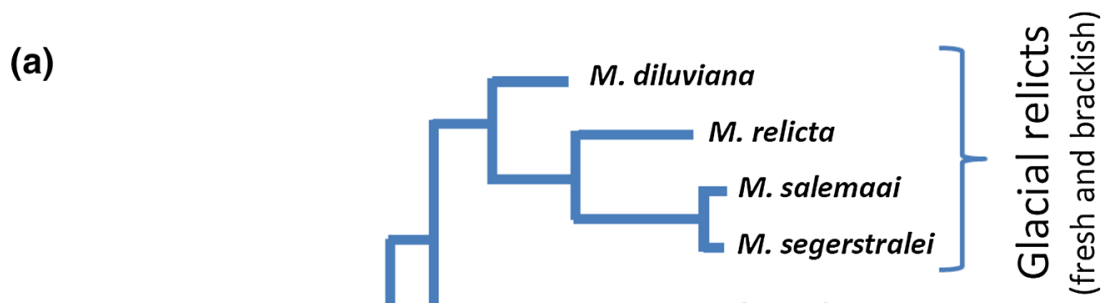

Caspian

Marine

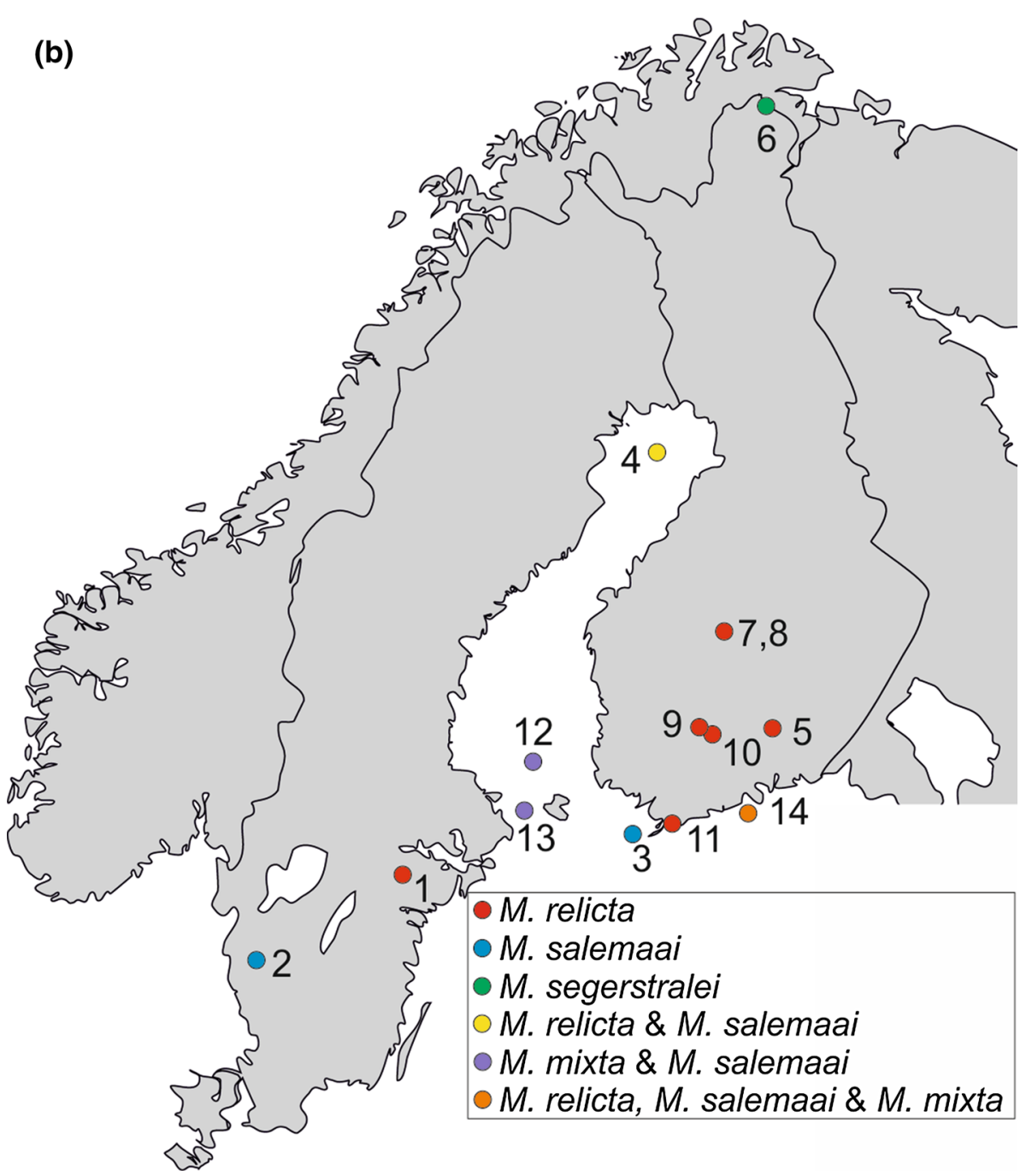




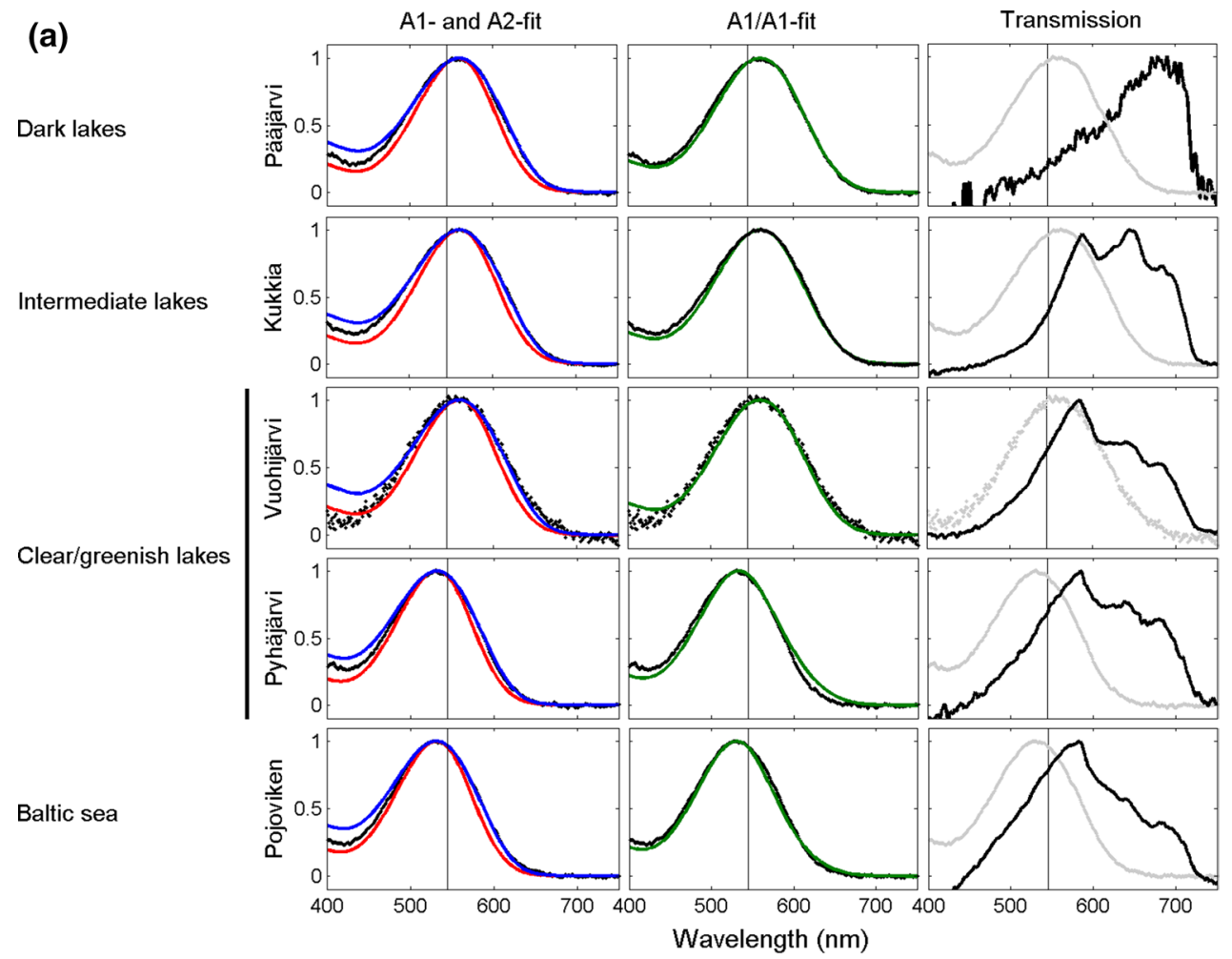

(b)

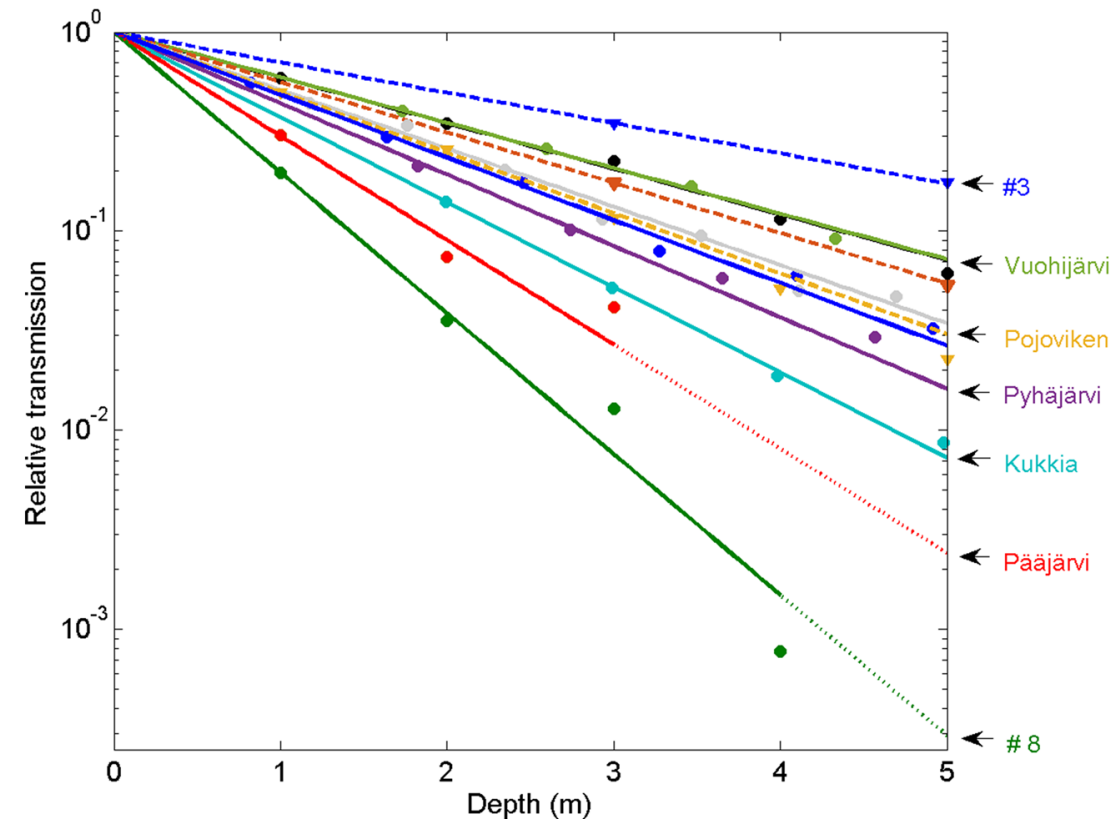

not allow us to isolate the absorbance of single photoreceptor cells (rhabdomeres), but provides the summed absorbance of several or all rhabdomeres in the rhabdom.

Spectra were basically similar in shape and could thus be characterized by a single parameter, the wavelength of maximum absorbance $\left(\lambda_{\max }\right)$, obtained by fitting the data with standard templates of Govardovskii et al. (2000) (hereafter referred to as GFRKD). Following the practice of Jokela-Määttä et al. (2005) and Audzijonyte et al. (2012) we used the single-parameter A2 template as a phenomenological descriptor, which provided good fits and yielded $\lambda_{\text {max }}$ in standardized fashion. However, as we now conclude that the broad "A2-like" spectra in fact arise from mixtures of two A1 pigments, we demonstrate that equivalent fits can be obtained with sums of two A1 templates in different proportions (Fig. 2a). While this allows spectral identification of the two component pigments, it is less useful for descriptive purposes, as fitting entails fixing three parameters: $\lambda_{\max }$ 
4 Fig. 2 a Columns 1 and 2: absorbance spectra (black) of single $M$. relicta individuals from four lake populations (rows 1-4) and one sea population (row 5). Each spectrum is an average of recordings from $\sim 10$ to 20 single rhabdoms of one individual. The smooth curves in column 1 are GFRKD templates for A2 pigments fitted to the data (blue) and for A1 pigments locked to the same $\lambda_{\max }$ values (red). The $\lambda_{\max }$ values, determined from the A2 fits, are (from top to bottom): $559.5 \mathrm{~nm}$ (location/population \#10 in Fig. 1b; Table 1), $560.3 \mathrm{~nm}$ (\#9), $559.8 \mathrm{~nm}$ (\#5), $534.3 \mathrm{~nm}$ (\#7) and $531.0 \mathrm{~nm}$ (\#11). In column 2 the same data have been fitted with linear sums of GFRKD templates for two A1 pigments $\left(P_{\mathrm{I}}\right.$ and $\left.P_{\mathrm{II}}\right)$. Thus the curves are defined by three parameters $\left[\lambda_{\max }\left(P_{\mathrm{I}}\right), \lambda_{\max }\left(P_{\mathrm{II}}\right),\left(P_{\mathrm{I}}: P_{\mathrm{II}}\right)\right]$. The values $\lambda_{\text {max }}\left(P_{\text {LWS }}\right)=570 \mathrm{~nm}$ and $\lambda_{\text {max }}\left(P_{\text {MWS }}\right)=525 \mathrm{~nm}$ were assumed to be the same for all, as they represent the same species $(M$. relicta), whereby $\left(P_{\mathrm{LWS}}: P_{\mathrm{MWS}}\right)=0.76: 0.24$ (rows 1-3: locations \#10, 9 and 5), 0.30:0.70 (row 4, location \#7), and 0.21:0.79 (row 5; location \#11). Column 3: the spectrum of downwelling light (black) at $1 \mathrm{~m}$ depth in the respective habitats (black). The recorded absorbance spectra from the two other columns have been included for comparison (light gray). In all panels, a vertical line has been drawn at $545 \mathrm{~nm}$ to facilitate distinction of "L-type" $\left(\lambda_{\max }>545 \mathrm{~nm}\right)$ and "S-type" ( $\left.\lambda_{\max }<540 \mathrm{~nm}\right)$ absorbance spectra (cf. Figure 3 ). b Light attenuation at the wavelength of maximal transmission (WMTL) as function of depth below surface in all the habitats where these measurements have been made (Table 1). Dashed lines and triangles refer to Baltic Sea habitats, full-drawn lines and circles to fresh-water habitats. Indicated by arrows are the five habitats of the samples in panel a, plus the clearest (location \#3, Baltic Sea) and darkest of all (\#8, Lake Mahlunjärvi). All functions have been normalized to 1 at the surface (i.e., $10^{\circ}$ at depth 0 ) to remove effects of varying daylight intensity at the times of measurement. Extrapolations beyond the last points where measurements could be made in the two darkest habitats (Pääjärvi and \#8) are marked by dotted lines

of both components, and the proportion of the two, leaving considerable room for trade-offs.

The MSP experiments involving spectrally selective bleaching of the visual pigments were carried out in the presence of hydroxylamine ( $\mathrm{pH} 6.5,50 \mathrm{mM}$ ) to prevent formation of metarhodopsins that would obscure the spectra of the native rhodopsins. Hydroxylamine binds the chromophore of the photoconverted pigment, forming an oxime with sufficiently short-wavelength-shifted absorbance spectrum not to interfere significantly with the peaks of the native visual-pigment spectra. For a detailed description of this method, the reader is referred to Zak et al. (2009).

\section{Light measurements in the habitats of the populations}

Absolute irradiance spectra were measured at several depths at locations \#5-11 with an OceanOptics JAZ portable spectrometer and a $20 \mathrm{~m}$ long optic cable with cosine collector. Measurements were done with the sensor directed both upwards and downwards, first just above the water surface and then at $1 \mathrm{~m}$ intervals down to a depth of $18 \mathrm{~m}$. We eliminated the effect of drift on the depths of measurements either by attaching a weight to the cable or by taking the angle of the cable into account in the calculations. A mean spectrum was calculated from the "up" and "down" measurements and smoothed by Gaussian convolution. The wavelength of maximal transmission of light (WMTL) was calculated as the mean of the peak wavelengths of all measurements where spectra rose above baseline noise in a wavelength range from 423 to $747 \mathrm{~nm}$. The light attenuation coefficient $k$ was determined by fitting an exponential to the intensity values at WMTL as function of depth. The transmitted light at WMTL at depth $x$ below surface is $I(x)=I_{0} \exp (-k x)$ where $I_{0}$ is the intensity at the surface and $x$ is depth in meters. The wavelength of mean transmission (MT) at different depths was calculated as the wavelength bisecting the area under the transmission spectrum (i.e., so that the integrated photon fluxes are equal above and below that wavelength). These values are given in Table 1.

\section{Calculation of quantum catch and conceptual signal-to noise ratio of rhodopsins as function of $\lambda_{\text {max }}$ in a given light environment}

Relative quantum catch (QC) as function of $\lambda_{\max }$ for A1 visual pigments $\left[\mathrm{QC}_{\text {rel }}\left(\lambda_{\text {max }}\right)\right]$ was calculated for the two well-studied populations $L_{\mathrm{p}}$ (\#10) at 1 and $3 \mathrm{~m}$ depth below surface, and $S_{\mathrm{p}}$ (\#11) at 4 and $8 \mathrm{~m}$ depth below surface. In lake habitat \#10, $3 \mathrm{~m}$ was the deepest point where a proper transmission spectrum could be measured; for sea habitat \#11, the depths chosen were those where the absolute irradiances matched those at 1 and $3 \mathrm{~m}$ in \#10. Relative quantum catch $\mathrm{QC}_{\text {rel }}\left(\lambda_{\max }\right)$ was obtained by convolution of normalized light transmission spectra with GFRKD A1 templates. The conceptual signal-to-noise ratio of the visual pigment as function of $\lambda_{\text {max }}, \operatorname{SNR}_{\text {dark }}\left(\lambda_{\max }\right)$, was calculated as described in Jokela-Määttä et al. (2007). Briefly, the pigment signal is $\mathrm{QC}_{\text {rel }}\left(\lambda_{\text {max }}\right)$ in the particular light environment, and the pigment noise is the Poisson standard deviation of its rate of spontaneous thermal activations, $F\left(\lambda_{\max }\right)$, as given by Ala-Laurila et al. (2004; Eqs. 4 and 8). The Poisson standard deviation is the square root of the mean, thus $\operatorname{SNR}_{\text {dark }}\left(\lambda_{\text {max }}\right)=\mathrm{QC}_{\text {rel }}\left(\lambda_{\text {max }}\right) / \sqrt{ } F\left(\lambda_{\text {max }}\right)$ (when both photoactivations and thermal activations are integrated over the same time interval).

\section{ERG recording}

Whole eye field potentials (electroretinograms, ERG) in response to flashes of light were recorded as described by Lindström and Nilsson (1988) and Pahlberg et al. (2005). Before experiments, the animals were kept in the dark and all preparation procedures were carried out under infrared light with the aid of an IR-viewer. After decapitation of the animal, the head was mounted in the specimen chamber, where it was bathed in brackish water from the Baltic Sea (salinity $\sim 0.5 \%$ ). ERG responses were DC recorded (bandwidth $0-300 \mathrm{~Hz}$ ) at $5{ }^{\circ} \mathrm{C}$. Under these conditions, 
Table 1 Summary of Mysis single-rhabdom absorbance spectra and water transmission properties for 15 populations of glacial-relict species from Fennoscandian lakes and different parts of the Baltic Sea, and for $3 \mathrm{M}$. mixta populations from the Baltic Sea (see map in Fig. 1b)

\begin{tabular}{|c|c|c|c|c|c|c|c|c|c|}
\hline & Location & Species & $\lambda_{\max }(\mathrm{nm})$ & WMTL & MT & $k$ & $N$ & $n$ & Opsin lineage $\mathrm{e}^{\mathrm{b}}$ \\
\hline 1 & Mjörn & M. salemaai & $556.5 \pm 1.2^{\mathrm{a}}$ & 585 & 611 & -0.7 & $5^{\mathrm{a}}$ & & II \\
\hline 2 & Båven & M. relicta & $555.5 \pm 0.3^{\mathrm{a}}$ & 579 & 582 & -0.5 & $5^{\mathrm{a}}$ & & II \\
\hline 3 & Klovaskär & M. salemaai & $525.4 \pm 0.3^{\mathrm{b}}$ & $565^{\mathrm{c}}$ & 562 & -0.4 & $6^{\mathrm{b}}$ & $18^{\mathrm{b}}$ & $\mathrm{I} / \mathrm{II}$ \\
\hline \multirow[t]{2}{*}{4} & \multirow[t]{2}{*}{ Bothnian bay } & M. salemaai & $521.2 \pm 0.4^{\mathrm{b}}$ & $580^{\mathrm{d}}$ & & & $3^{\mathrm{b}}$ & $19^{\mathrm{b}}$ & $\mathrm{I} / \mathrm{II}$ \\
\hline & & M. relicta & $535.0 \pm 1.2^{\mathrm{b}}$ & & & & $2^{\mathrm{b}}$ & $21^{\mathrm{b}}$ & II \\
\hline 5 & Vuohijärvi & M. relicta & $556.0 \pm 0.4^{\mathrm{b}}$ & 584 & 610 & -0.5 & $7^{\mathrm{b}}$ & $15^{\mathrm{b}}$ & II \\
\hline 6 & Pulmankijärvi & M. segerstralei & $562.1 \pm 0.3^{\mathrm{b}}$ & 583 & 600 & -0.6 & $12^{\mathrm{b}}$ & 5 & I \\
\hline 7 & Pyhäjärvi & M. relicta & $536.6 \pm 2.6$ & 583 & 616 & -0.7 & 3 & 22 & \\
\hline 8 & Mahlunjärvi & M. relicta & $563.2 \pm 0.9$ & 700 & 682 & -1.6 & 9 & 15 & \\
\hline 9 & Kukkia & M. relicta & $560.6 \pm 0.5$ & 648 & 637 & -1.0 & 9 & 21 & \\
\hline 10 & Pääjärvi & M. relicta & $561.0 \pm 0.3$ & 686 & 668 & -1.2 & 3 & 25 & \\
\hline 11 & Pojoviken & M. relicta & $535.0 \pm 2.0$ & 582 & 594 & -0.8 & 9 & 17 & II \\
\hline \multirow[t]{2}{*}{12} & \multirow[t]{2}{*}{ Bothnian Bay south } & M. salemaai & $526.2 \pm 0.8$ & $555^{\mathrm{d}}$ & & & 10 & 19 & \\
\hline & & M. mixta & 517.1 & & & & 1 & 25 & \\
\hline \multirow[t]{2}{*}{13} & \multirow[t]{2}{*}{ Sea of Åland } & M. salemaai & $523.5 \pm 1.3$ & $560^{\mathrm{d}}$ & & & 4 & 25 & \\
\hline & & M. mixta & $520.6 \pm 0.1$ & & & & 2 & 25 & \\
\hline \multirow[t]{3}{*}{14} & \multirow[t]{3}{*}{ Gulf of Finland } & M. relicta & $550.1 \pm 1.7$ & $565^{\mathrm{d}}$ & & & 2 & 16 & \\
\hline & & M. salemaai & $528.5 \pm 2.9$ & & & & 3 & 16 & \\
\hline & & M. mixta & $524.5 \pm 2.7$ & & & & 2 & 10 & \\
\hline
\end{tabular}

Opsin lineage: different opsin genes interpreted as alleles of the same locus by Audzijonyte et al. (2012). See "Discussion"

Superscripts: data reported in ${ }^{\text {a }}$ Jokela-Määttä et al. (2005), ${ }^{\mathrm{b}}$ Audzijonyte et al. (2012), and ${ }^{\mathrm{c}}$ Audzijonyte et al. (2005), and ${ }^{\mathrm{d}}$ estimates based on literature

$\lambda_{\max }(\mathrm{nm})$, mean \pm SEM of $\lambda_{\max }$ of all individuals studied in a population, WMTL wavelength of maximal transmission of light in the water column; MT, wavelength of mean transmission; $k\left(\mathrm{~m}^{-l}\right)$, attenuation coefficient of light in the water column. The intensity of light at WMTL as function of depth below surface is $I(x)=I_{0} \exp (-k x)$ where $x$ is depth in meters and $\mathrm{I}_{0}$ is the intensity at the surface; $N$, number of individual animals studied; $n$, mean number of rhabdoms measured per individual the preparation was very stable even for $24 \mathrm{~h}$. The Inset in Fig. 6 shows the geometry, recordings being done from one of the eyes in situ on the head. An extracellular glass pipette (tip diameter ca $10 \mu \mathrm{m}$ ) filled with $100 \mathrm{mM} \mathrm{NaCl}$ and equipped with an $\mathrm{Ag} / \mathrm{AgCl}$ electrode was advanced to a depth of 40-50 $\mu \mathrm{m}$ through a small hole made by a microneedle in the cornea of the dorsal region, while an $\mathrm{Ag} / \mathrm{AgCl}$ wire in the bath served as reference.

The ERG was used for studying the polarization sensitivity of the eye and its correlation with short- and longwavelength-sensitive response components. The stimulus protocol involved continuous alternation of flashes from a blue $(460 \mathrm{~nm})$ and a red $(630 \mathrm{~nm})$ LED. A linear polarizer was inserted above the eye perpendicularly to the beam, which impinged on the eye perpendicularly to its dorsofrontal surface (see inset in Fig. 6). The polarizer was rotated through $360^{\circ}$ in steps of $9^{\circ}$ after each pair of blue and red flashes. The intensities of the blue and red LEDs were initially set to elicit responses of equal amplitude at the "start" $\left(0^{\circ}\right)$ orientation of the polarizer.

Since estimation of photoisomerization rates in the intact Mysis eye is difficult due to screening pigments and eye geometry, and since absolute values were not needed here, flash intensities $\left(I_{\mathrm{F}}\right)$ are expressed relative to a "threshold" flash intensity $\left(I_{\mathrm{FT}}\right)$, defined as that which (in each preparation) elicited an ERG criterion response of $20 \mu \mathrm{V}$ in the dark-adapted state. Both LEDs were driven at constant power, and flash intensity (strictly speaking, photon dose) was varied using pulses of four different durations: 0.02 , $0.2,2.0$, and $20 \mathrm{~ms}$. The longest pulse is not "an infinitely brief flash" from the viewpoint of response shape, but this entailed no disadvantage, as minor changes in response shape with changes in the length of brief pulses are of no concern here. Given the limitations of our light sources, this was an acceptable way of getting up high enough on the (saturating) response-amplitude vs. stimulus-intensity function.

\section{Determination of chromophore identity}

Chromophore identity was determined by HPLC as described in detail in Belikov et al. (2014). Briefly, eye extracts were run against references consisting of the same extracts to which had been added either pure A1 or pure A2 
chromophore. The added chromophores produced significant and easily identifiable peaks (Fig. 4).

\section{Ethical statement}

None of the mysid species studied is endangered in the sampling areas (see map in Fig. 1b). M. relicta (sensu lato) are in fact the most common macrocrustaceans in Finnish waters. Under Finnish legislation, no permit is needed for sampling of invertebrates. Public access to all areas is guaranteed according to the general principle of "everyman's right" (common rights) regardless of ownership (private/ state/municipal), unless explicit and precisely specified regulations apply (which is not the case here). Common rights include unrestricted sampling of such invertebrate species that are not defined as endangered, and the land owner's permission is not required for these purposes.

\section{Results}

\section{Bimodal distribution of single-rhabdom absorbance spectra in the glacial-relict mysids}

Absorbance spectra were recorded by MSP from single dark-adapted rhabdoms of animals from 15 populations representing all three European glacial-relict Mysis species (see Fig. 1b). Figure 2a shows examples of spectra from single individuals of five populations of $M$. relicta. Each row represents one population/habitat. Rows 1-4 from top roughly span the optical range of fresh-water habitats encountered, from "dark brown" to "clear greenish" as initially classified by visual inspection. Row 5 represents the coastal Baltic Sea. The first two columns in each row show the same spectra (averaged from 10 to 20 single-rhabdom recordings in each case) fitted with different curves. The blue and red curves in column 1 are GFRKD templates for, respectively, pure A2 and pure A1 pigments The blue curves (A2 templates), used previously by Jokela-Määttä et al. (2005) and Audzijonyte et al. (2012), are seen to provide good fits. By contrast, the red curves (A1 templates), here locked to the same $\lambda_{\text {max }}$, are systematically too narrow. This would in no way improve if the fits were based instead on the long-wavelength limb of the spectrum, as often preferred for spectra of lower quality.

Column 2, however, shows that good fits can also be achieved on the assumption that spectra represent the summed absorbance of two A1 pigments $\left(P_{\mathrm{I}}\right.$ and $\left.P_{\mathrm{II}}\right)$. Below, we argue that this is the true situation. Fitting sums of templates is less attractive if the purpose is only to provide a simple empirical description, however, since it involves three parameters: $\lambda_{\max }\left(P_{\mathrm{I}}\right), \lambda_{\max }\left(P_{\mathrm{II}}\right)$ and the ratio $\left(P_{\mathrm{I}}: P_{\mathrm{II}}\right)$ (see the legend to Fig. $\left.2 \mathrm{a}\right)$, with significant room for trade-offs. Therefore, the single-parameter GFRKD A2 template was used throughout as a phenomenological descriptor for the purpose of determining $\lambda_{\max }$ of recorded spectra in a standardized way, commensurate also with the values given by Jokela-Määttä et al. (2005) and Audzijonyte et al. (2012) (Fig. 3; Table 1).

Column 3 shows the light spectrum (black) measured in each habitat at $1 \mathrm{~m}$ depth together with the single-rhabdom absorbance spectrum (light gray) of the corresponding sample. The vertical line drawn at $545 \mathrm{~nm}$ in all panels makes it easy to see, e.g., that the spectral absorbance of the population in row 1 (Lake Pääjärvi, $L_{\mathrm{p}}$ ) is significantly red-shifted compared with that of the population in row 5 (Pojoviken of the Baltic Sea, $S_{\mathrm{p}}$ ), and that the difference seems to correlate with the difference between the spectral light transmission of the two habitats. Indeed, rows 1 and 5 represent the two populations $L_{\mathrm{p}}$ and $S_{\mathrm{p}}$ where an "adaptive" shift in eye (ERG) spectral sensitivity was originally described by Lindström and Nilsson (1988).

The situation becomes much less clear, however, when the three other lakes in Fig. 2a (rows 2-4) are considered. Their spectral transmissions differ rather little from that of Pojoviken, yet the absorbance spectra recorded from animals from two of them (including the least red-shifted Lake Vuohijärvi, row 3 from top) are similar to $L_{\mathrm{p}}$, and only the Lake Pyhäjärvi population (row 4 from top) resembles $S_{\mathrm{p}}$. In fact, the last-mentioned is the only one among all eight fresh-water populations studied here that did not have the long-wavelength-shifted $\left(L_{\mathrm{p}}\right)$ type of absorbance spectrum.

Figure $2 \mathrm{~b}$ shows the general light attenuation as function of depth in the habitats included in Fig. 2a and several others from Table 1. The lakes labeled "clear/greenish" in panel (a) are similar to the Baltic Sea location Pojoviken not only in the spectral distribution of light, but also in the relatively high general light transmission. Note particularly that Lake Vuohijärvi is not only spectrally similar to Pojoviken, but has even clearer water. Only the Baltic Sea location \#3 is clearer.

The consistent lake/sea (henceforth $L / S$ ) dichotomy in absorbance spectra, which overrides most specific correlations with illumination spectra, is illustrated by Fig. 3 . Panel (a) shows the distribution of individual $\lambda_{\max }$ values across six $L$ populations (red) and six $S$ populations (blue) representing all three species, panel (b) shows population means \pm standard deviations of all 19 populations in Table 1 (i.e., including also M. mixta besides the three glacial-relict species) as functions of the WMTL in the habitat.

The $\lambda_{\max }$ values form two distinct clusters centered on ca 530 and $560 \mathrm{~nm}$, respectively (Fig. 3a). Six M. relicta individuals (three "red" from location \#7 and three "blue" from locations \#11 and \#14 in Fig. 1b) fall in the "wrong" cluster, but even so there remains an empty $\lambda_{\max }$ interval without a single individual $(540-545 \mathrm{~nm})$. The bimodality 

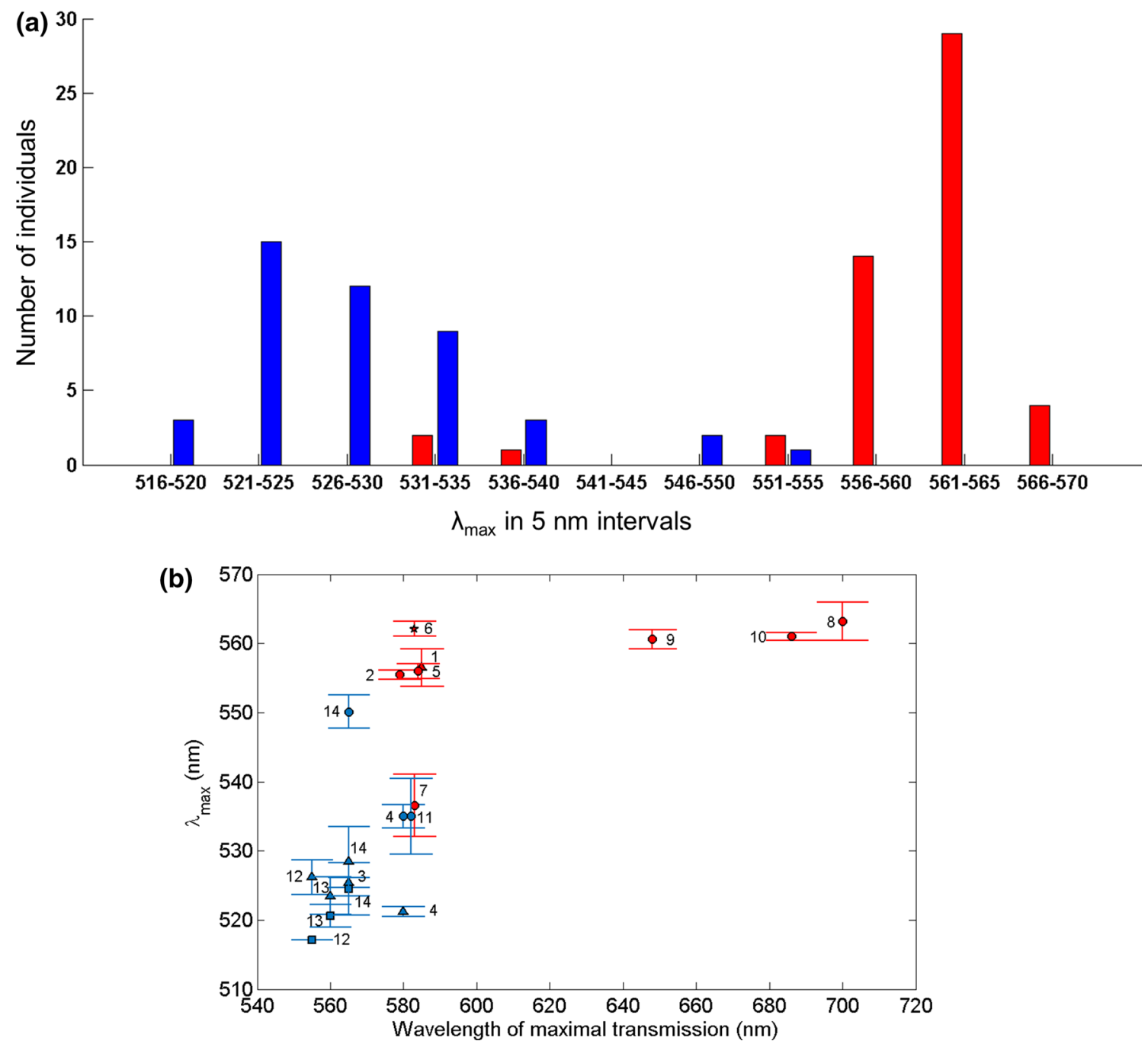

Fig. 3 a Distribution of $\lambda_{\max }$ values of individual animals from six lake (red) and six sea (blue) populations (locations/populations \#3-14 in Fig. 1b; Table 1). These mainly constitute two separate clusters. The exceptions (red bars in the short-wave cluster and blue bars in the long-wave cluster) are $M$. relicta individuals from location \#7 (Lake Pyhäjärvi, three individuals) and locations \#11 and \#14 (Baltic Sea at the south coast of Finland, $1+2$ individuals), respectively. b Mean $\lambda_{\max } \pm$ SD for all the 19 Mysis populations listed in Table 1, plotted as function of the wavelength of maximum transmission of

appears even crisper in terms of population means, summarized in Table 1 (mean \pm SEM) and Fig. $3 b$ (mean \pm SD). There is no population with mean $\lambda_{\max }$ in the interval 537$550 \mathrm{~nm}$, but two M. relicta populations, \#7(L) and \#14(S), fall in the "wrong" group. Moreover, if the generic association of S-type sensitivity with brackish-water environments and L-type sensitivity with fresh-water environments is factored out, there remains at most a hint of residual correlation of population mean $\lambda_{\max }$ with WMTL (Fig. 3b). To appreciate the dominance of the general $L / S$ dichotomy, it may be noted that within either the $L$ or the $S$ population light (WMTL) in the respective habitats. The values have been calculated from all individual mean values within each population. The numbers correspond to the map in Fig. $1 \mathrm{~b}$ and Table 1; in cases where there are several species from the same location, the species are distinguished by different symbols: circles $M$. relicta, triangles $M$. salemaai, squares M. mixta. While there is no clear correlation between $\lambda_{\max }$ and WMTL, all populations in brown lakes (rightmost points) have L-type spectral sensitivities

group, the maximal difference in mean $\lambda_{\max }$ between two different species, M. relicta and M. salemaai, is only $14 \mathrm{~nm}$ in spite of substantial divergence of their opsin genes (Audzijonyte et al. 2012). By contrast, the $L_{\mathrm{p}}$ and $S_{\mathrm{p}}$ populations of $M$. relicta differ by $26 \mathrm{~nm}$, although no opsin gene differences translating into amino acid substitutions have been found.

Having established the nearly complete $L / S$ dichotomy in 15 populations of three species (Fig. 3; Table 1), we proceeded to identify molecular and cellular mechanisms in one well-established model population pair $\left(L_{\mathrm{p}}\right.$ and $\left.S_{\mathrm{p}}\right)$ of 
one species, M. relicta. We shall argue that the conclusions are likely to hold for all populations across species.

\section{The bimodal distribution of single-rhabdom absorbance spectra is not due to a chromophore difference}

The most obvious hypothesis for explaining a pervasive 20-30 nm spectral shift between $L$ and $S$ populations would be that they use different chromophores in the same opsin. The A1 $\leftrightarrow$ A2 (rhodopsin-porphyropsin) system underlies "fast" tuning of spectral sensitivity in fishes and amphibians (e.g., Schwanzara 1967; Bridges 1972; Enright et al. 2015), and is known to be used also by at least one crustacean species, the fresh-water crayfish Procambarus clarkii (Suzuki et al. 1984, 1985, 1993). In Procambarus, like in a great number of vertebrate species, the balance of the two chromophores is regulated by environmental factors, primarily light and temperature (Suzuki et al. 1985). In the $\lambda_{\max }$ range relevant here $(520-560 \mathrm{~nm})$, replacing A1 by A2 in the same opsin is expected to cause a red shift of about the right magnitude $(\sim 30 \mathrm{~nm})$ (Dartnall and Lythgoe 1965; Hárosi 1994).

Chromophore identity was determined by HPLC in our main model population pair $L_{\mathrm{p}}$ and $S_{\mathrm{p}}$ (\#10 and \#11 in Table 1; Fig. 1b) as described by Belikov et al. (2014) (see "Materials and methods"). Eye extracts were run against the same extracts supplemented with pure A1 and A2 chromophores. The unambiguous result (Fig. 4) is that the eyes of both populations contain only A1, with no measurable trace of A2. There are good reasons to think that this conclusion can be generalized to all populations and species (see "Discussion").

\section{The different absorbance spectra of $L_{\mathrm{p}}$ and $S_{\mathrm{p}} M$. relicta are due to different proportions of two rhodopsins}

As shown in Fig. 2, the "A2-like" broad shape of the absorbance spectra can be generated by sums of A1 templates. Since the eyes contain only A1 chromophore, the spectra must indeed arise from mixtures of A1 pigments. In order to investigate directly whether two rhodopsins differing in $\lambda_{\max }$ are present we performed experiments where changes in MSP absorbance spectra were measured at different stages of spectrally selective bleaching of single rhabdoms. These experiments were done in the presence of hydroxylamine, which will remove metarhodopsins (dominant $\lambda_{\max } \sim 490 \mathrm{~nm}$ ) liable to obscure the absorbance spectra of remaining native rhodopsins. Under these conditions the final bleaching product is opsin and retinal oxime, which absorbs at wavelengths short enough not to interfere significantly $\left(\lambda_{\max }<390 \mathrm{~nm}\right.$; see Bridges 1972; Zak et al. 2009; cf. "Materials and methods").
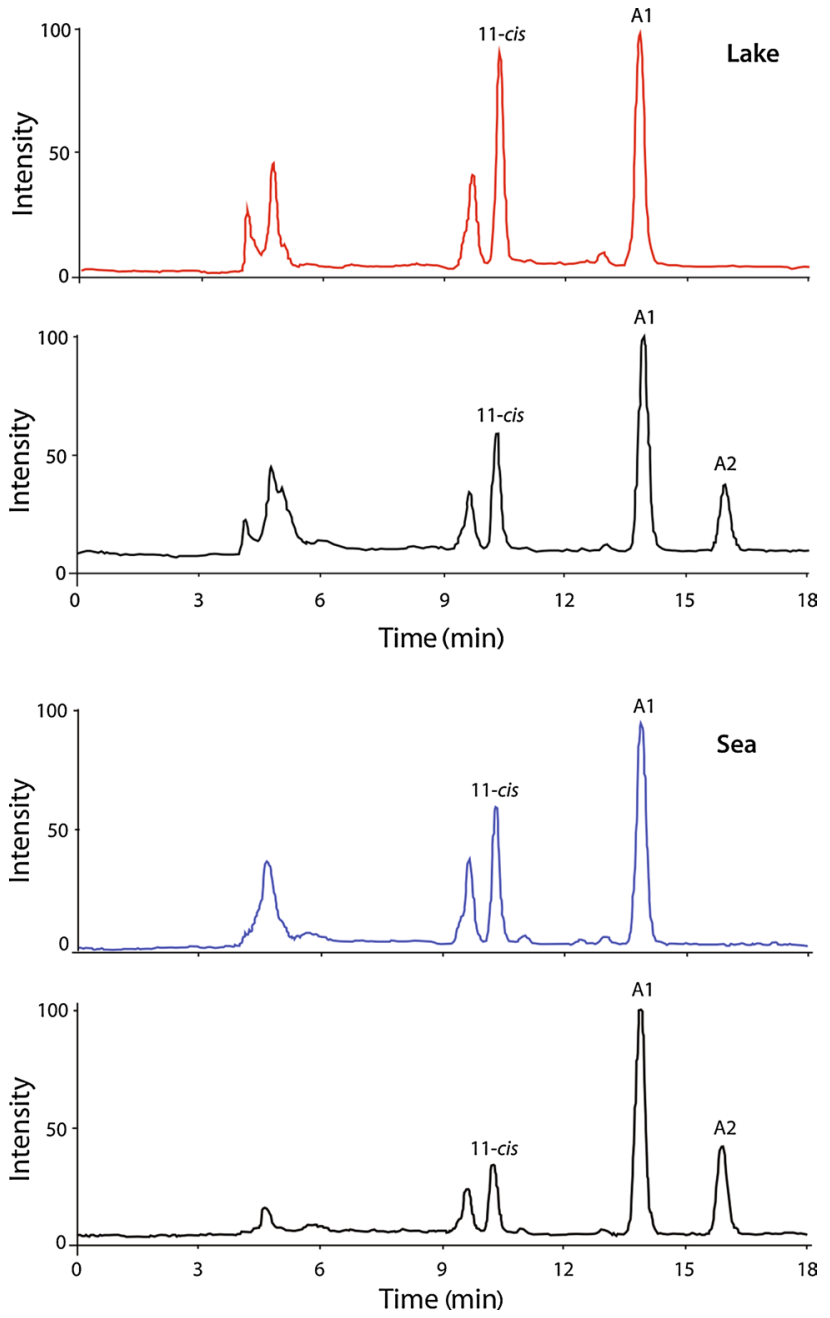

Fig. 4 HPLC analysis of eye extracts of $L_{\mathrm{p}}$ (red trace, top) and $S_{\mathrm{p}}$ (blue trace, bottom) M. relicta. Each extract is compared with the same extract to which have been added pure chromophores A1 and A2 (black traces). In neither population does the native eye extract show any signal corresponding to the A2 peak in the black reference trace (Belikov et al. 2014); hence, both use only chromophore A1

Figure 5 shows a family of absorbance spectra of an $L_{\mathrm{p}}$ rhabdom recorded by MSP at different stages of partial bleaching first with long-wavelength light $(650 \mathrm{~nm})$, then with shorter wavelength light $(560 \mathrm{~nm})$. Several epochs of $650 \mathrm{~nm}$ bleaching not only depressed the overall absorbance in a graded manner, more importantly, it shifted the absorbance peak towards shorter wavelengths (blue and green traces). After $640 \mathrm{~s}$ of bleaching, a low peak (green) remained around $530 \mathrm{~nm}$ that was virtually unaffected by $500 \mathrm{~s}$ of further exposure to $650 \mathrm{~nm}$ light. However, a final phase of $560 \mathrm{~nm}$ exposure made the peak disappear completely (red trace), confirming its origin in a second, bleachable visual pigment. The $\lambda_{\max }$ and amplitudes of the two bleachable spectral components were read at the points where the distance between the spectra prior to and 


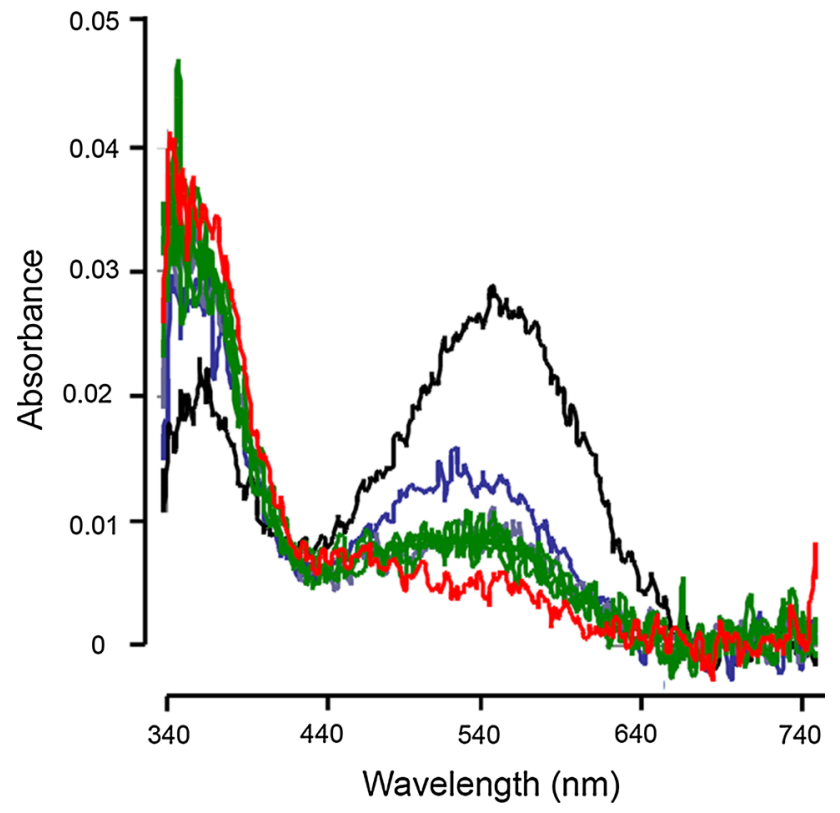

Fig. 5 MSP absorbance spectra recorded from a single $L_{\mathrm{p}}$ rhabdom at different stages of extended exposures to strong $650 \mathrm{~nm}$ (several epochs) and thereafter $560 \mathrm{~nm}$ light in the presence of hydroxylamine, which results in spectrally selective bleaching of the visual pigments. Black curve dark adapted state at the beginning of the experiment; blue curve after bleaching with $650 \mathrm{~nm}$ light for $340 \mathrm{~s}$; green curves semi-steady state after bleaching with $650 \mathrm{~nm}$ light for totally $1140 \mathrm{~s}(340+300+150+100+150+100 \mathrm{~s})$, red curve final state after additional bleaching with $560 \mathrm{~nm}$ light for $300 \mathrm{~s}$ $(100+100+100 \mathrm{~s})$. The hydroxylamine serves to remove metarhodopsins, the absorbance spectra of which would overlap with those of native rhodopsins. The rise in absorbance below $400 \mathrm{~nm}$ is due to the retinal oxime formed as hydroxylamine binds the $\mathrm{A} 1 \mathrm{chromophore.}$ $\left(\lambda_{\max } \approx 368 \mathrm{~nm}\right.$; see Bridges (1972))

after extended bleaching is greatest. For the main component, this is the point of greatest distance between the black curve and the curve unresponsive to extended $650 \mathrm{~nm}$ exposure (taken as the middle of the many superimposed recordings seen as a broad green noise band), at ca. 565$570 \mathrm{~nm}$. For the second component, this is the point of greatest distance between the latter and the final photostable baseline (red), at ca. $530-535 \mathrm{~nm}$. The amplitude ratio is roughly 5:1. This might in principle be translated into a molecular ratio of a long-wavelength sensitive (LWS) and a middle-wavelength-sensitive (MWS) rhodopsin with $\lambda_{\max } \approx 565-570$ and 530-535 nm, respectively. The best fits for combinations of two A1 pigments, based on GFRKD templates, across all $M$. relicta populations, when the two components are constrained to have the same $\lambda_{\max }$ values in all (cf. the fits in the second column of Fig. 2), suggested that LWS and MWS $\lambda_{\max }$ might lie even further apart $(570$ and $525 \mathrm{~nm})$. These estimates are fraught with considerable uncertainty, however. Given that no differences in the opsin genes translating into amino acid differences have been detected between $L_{\mathrm{p}}$ and $S_{\mathrm{p}}$ (Audzijonyte et al. 2012; see "Discussion"), we attribute the variability to technical limitations.

Experimental isolation of MWS and LWS components by spectrally selective bleaching could not be successfully performed on $S_{\mathrm{p}}$ rhabdoms. Spectral changes even due to full bleaching of the minority (LWS) pigment are difficult to measure reliably, and the majority (MWS) pigment cannot be selectively targeted without simultaneous bleaching of the LWS pigment. Figure 5 therefore, essentially offers a "proof of principle", i.e., experimental support for the idea that the broad A2-like spectra can be decomposed into two A1 spectra. For a comprehensive picture of pigment composition in all populations ( $L$ as well as $S$ ) of all species we relied on A1/A1 template-fitting to unbleached rhabdoms. A cautious conclusion is that the two components of M. salemaai lie at ca. $10 \mathrm{~nm}$ shorter wavelengths compared with those of $M$. relicta, best estimates being $\lambda_{\max }\left(P_{\mathrm{LWS}}\right) \approx 560$ and $\lambda_{\text {max }}\left(P_{\mathrm{MWS}}\right) \approx 515$. The estimated $\left(P_{\mathrm{LWS}}: P_{\mathrm{MWS}}\right)$ ratios are even more uncertain, as they depend strongly on the choice of $\lambda_{\max }$, but for the given $\lambda_{\max }$ values, the fitting suggests ca. $3: 1$ in $L$ populations and 1:3 in $S$ populations.

\section{The two rhodopsins are segregated into different cells with different polarization sensitivities}

Given that $M$. relicta possesses two spectrally different visual pigments, their function will crucially depend on whether they are homogeneously mixed in the same photoreceptor cells (albeit in different proportions in different populations), or partly or wholly segregated into different cells. In the former case, adjusting their proportions would only serve tuning of the overall spectral sensitivity of the eye; in the latter case they could also form the basis for dichromatic wavelength discrimination. Our MSP technique does not generally allow us to resolve the absorbance of single photoreceptor cells within a rhabdom. Therefore, we studied this question electrophysiologically by ERG, using polarized light for stimulation.

A common paradigm for separation of visual mechanisms with different spectral sensitivities is using spectrally selective light-adaptation (Stiles 1949). This route was taken by Zak et al. (2013), who found that "red" adaptation desensitized "red" responses more strongly than "blue" responses and took this as evidence that pigment proportions differ between cells. If all cells contained the same mixture, they argued, response changes would be independent of the wavelengths of adapting and testing lights and depend only on the rates and numbers of photoisomerizations from the background and the probe flash (the principle of univariance). While this conclusion would be valid for vertebrates, the evidence may not be compelling for arthropods, where bidirectional photoconversion between 
rhodopsin and (shorter wavelength sensitive) metarhodopsin is common. "Red" adaptation might then suppress "red" responses relative to "blue" responses just because the rhodopsin:metarhodopsin ratio changes.

Here we approached the question by studying wavelength-dependent differences in the polarization sensitivity of the eye. Arthropod photoreceptors potentially support discrimination of polarization angles, as light with the e-vector parallel to the microvilli is best absorbed. Photoreceptor cells with microvilli well-oriented in one plane will exhibit strong polarization selectivity, whereas photoreceptor cells with microvilli oriented in several directions, or higher order neurons summing responses from several photoreceptors with different microvillar orientations, will show little or no polarization selectivity. Thus comparison between (groups of) photoreceptors differing in microvillar orientation may form the basis for polarization discrimination (see, e.g., Fein and Szuts 1982).

We tested for polarization selectivity in general, and specifically for possible differences in the polarization preference of LWS- vs. MWS-driven responses, by presenting the eye with alternating flashes of linearly polarized "blue" $(460 \mathrm{~nm})$ and "red" $(660 \mathrm{~nm})$ light. The blue and red flash intensities were initially set to elicit responses of equal size at one orientation of the linear polarizer (relative log flash intensities $I_{\mathrm{F}}$ set such that $\log I_{\mathrm{F}} I_{\mathrm{TF}}=3$, see "Materials and methods"). Blue and red flashes of these fixed intensities were alternated at $0.3 \mathrm{~s}$ intervals, while the polarizer was turned through $360^{\circ}$ in $9^{\circ}$ steps after each blue-red flash pair.

Recordings from both an $L_{\mathrm{p}}$ and an $S_{\mathrm{p}}$ eye are shown in Fig. 6. The eyes of both populations showed clear polarization sensitivity correlating with flash wavelength. In $L_{\mathrm{p}}$, the blue response was strongly polarization-dependent (Fig. 6, top trace). It changed in both amplitude and shape, indicating changes not only in the strengths of underlying currents, but also a geometrical redistribution. This might suggest more complex interactions between cell types, but given the approximate constancy of the red response, the most parsimonious interpretation is that the polarization sensitivity originates in the MWS cells. In $S_{\mathrm{p}}$, on the contrary, it was the red response, mediated by LWS cells, that showed polarizationdependence (Fig. 6, bottom trace), whereas the blue response (mainly from MWS cells) stayed approximately constant.

Summarizing, it appears that the cells dominated by the minority pigment are the ones that primarily mediate polarization discrimination in both populations (MWS in $L_{\mathrm{p}}$ and LWS in $S_{\mathrm{p}}$ ), presumably by having microvilli well-oriented in a single plane. It may be noted that the best differentiation in both cases occurred for light polarized in the sagittal plane of the animal. With respect to precise interpretation of the ERG results, we need to make two cautionary remarks, however. First, even in case red responses originate exclusively in LWS cells, responses to blue cannot originate exclusively in MWS cells, but will necessarily contain an LWS-cell component because of the overlap of spectral sensitivities. Second, the ERG is an ohmic field potential reflecting changes in all appropriately oriented extracellular currents as well as resistance changes in the eye tissue, and the relation between cell processes and ERG voltage may be quite complex (see Donner et al. 1992).

\section{Discussion}

\section{Mysis spectra form two clusters that mainly correlate with fresh- vs. brackish-water habitats}

Our comparison of whole rhabdom absorbance spectra from a large and diverse sample of glacial-relict Mysis (15 populations representing three species) yielded three principal results. First, the spectra show a strongly bimodal distribution, with two non-overlapping $\lambda_{\max }$ clusters centered on ca 530 and $560 \mathrm{~nm}$. Second, the shorter wavelength cluster mainly comprises brackish-water populations ("sea", $S$ ) and the longer wavelength cluster fresh-water populations ("lake", $L$ ), with only two exceptions (one $L$ and one $S$ population). Third, within the clusters there is no consistent correlation of mean population $\lambda_{\max }$ and the spectral properties of the habitat. Against this general background, we have endeavored to dissect underlying mechanisms in one $S / L$ population pair, $M$. relicta from Pojoviken of the Baltic Sea and from Lake Pääjärvi (populations $S_{\mathrm{p}}$ and $L_{\mathrm{p}} ; \# 11$ and \#10). We argue that the mechanistic conclusions from this model pair can be generalized to all species and populations, and this leads to a new hypothesis regarding the origin of the bimodal $\lambda_{\max }$ distribution.

\section{Two A1 pigments are expressed in different proportions not correlating with the light environments}

First, it was shown that the spectral difference between $L_{\mathrm{p}}$ and $S_{\mathrm{p}}$ rhabdoms is not due to different chromophore usage, but that both use only the A1 chromophore (Fig. 4). We think that this result is likely to hold for all species/populations considered here. They have all experienced similar challenges involving repeated switches between fresh- and salt water conditions and would presumably have had continuous use for the chromophore exchange mechanism, had it been available. Had there been an ancestral A1 $\leftrightarrow$ A2 system (which would have been retained in some of the species/populations), it would hardly have been lost specifically in the particular line leading to our model $M$. relicta population pair, which would then (in a remarkably short time) have reinvented a similar spectral shift by a different mechanism. An almost equally unlikely scenario is that the special biochemical machinery needed, involving a physiologically 
Fig. 6 Changes in ERG responses of $L_{\mathrm{p}}$ and $S_{\mathrm{p}}$ eyes to alternating red and blue flashes of constant intensity as function of the plane of linear polarization of the stimulating light. Inset recording configuration. Top panel responses of $L_{\mathrm{p}}$ eye. The angular orientation of the polarizer is indicated above the trace. Red and blue flashes alternate; the responses that change as function of the plane of polarization are responses to blue flashes. The amplitudes of responses to red flashes are approximately constant. Scale bars $400 \mu \mathrm{V}$ (vertical) and $5 \mathrm{~s}$ (horizontal). Bottom panel responses of $S_{\mathrm{p}}$ eye. The responses that change as function of the plane of polarization are responses to red flashes.

The amplitudes of responses to blue flashes are approximately constant. Scale bars $100 \mu \mathrm{V}$ and $5 \mathrm{~s}$. Initially the red and blue flashes were set to give responses of equal amplitude at one orientation of the polarizer (marked $0^{\circ}$ or $180^{\circ}$ ), as seen for the first two and final two flash pairs in both records. Flash intensities were $3 \log$ units above the respective threshold intensities $\left(\log I_{\mathrm{F}} / I_{\mathrm{TF}}=3\right.$; the absolute intensity values were different for red and blue as well as for $L_{\mathrm{p}}$ and $S_{\mathrm{p}}$ ). See Text for further details
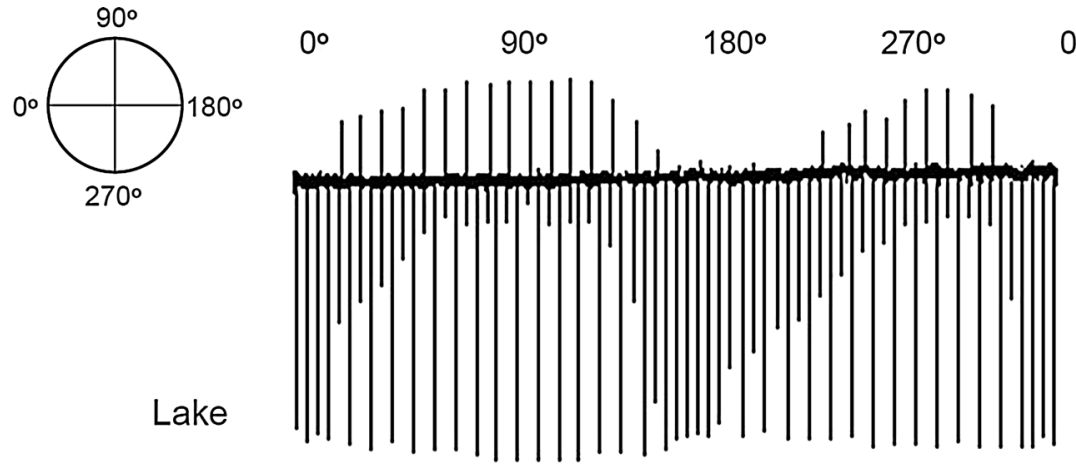

$0^{\circ}$

Lake
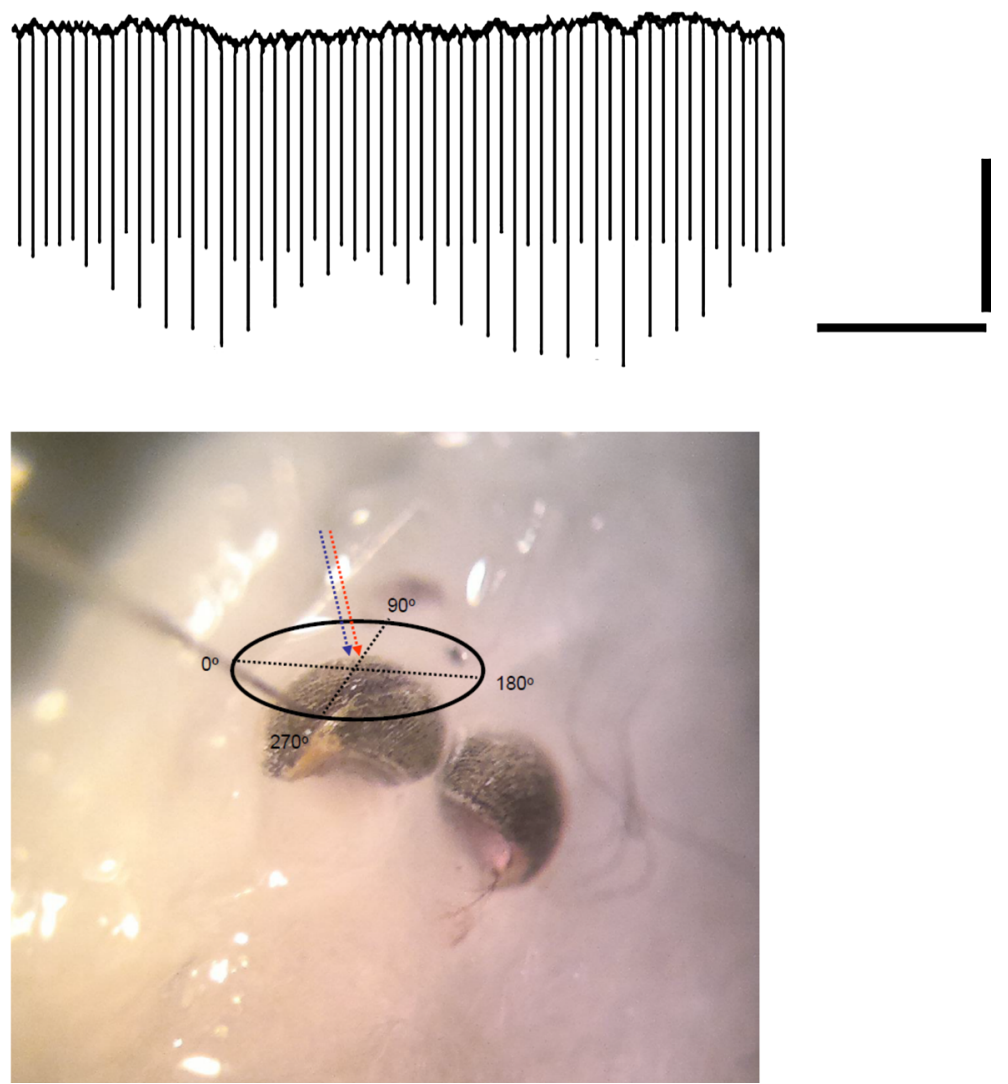

regulated dehydrogenase such as Cyp27c1 in vertebrates (Enright et al. 2015), should have evolved ab initio in some of the sibling species. Although there might in principle exist, e.g., seasonal variation that has escaped our notice (cf. for example Temple et al. 2006), it should be remembered that the only well-established example of the A1 $\leftrightarrow$ A2 system in crustaceans is the freshwater decapod Procambarus clarkii (Suzuki et al. 1984, 1985, 1993), which differs from the primarily marine mysids in many respects. Thus the present result from the $L_{\mathrm{p}}$ to $S_{\mathrm{p}}$ population pair of $M$. relicta strongly suggests that none of the species or populations have the $\mathrm{A} 1 \leftrightarrow \mathrm{A} 2$ system for shifting spectral sensitivity.

Second, it was shown that at least the $L_{\mathrm{p}}$ population achieves the spectral difference by expressing two pigments (LWS and MWS) in unequal proportions. If it is accepted that none of the species use A2 chromophore, the similar broad shape of all spectra suggest that these can be similarly decomposed into two A1 spectra. Fitting sums of two GFRKD A1 templates to the recorded spectra of all populations, assuming that the two components are the same within the same species, yielded best estimates $\lambda_{\text {max }}\left(P_{\text {LWS }}\right) \approx 570 \mathrm{~nm}$ and $\lambda_{\text {max }}\left(\mathrm{P}_{\mathrm{MwS}}\right) \approx 525 \mathrm{~nm}$ for $M$. relicta. Several opsin sequence differences have been found between the three species $M$. relicta, M. salemaai and M. segerstralei (Audzijonyte et al. 2012). Consistent with this, the best fits of two A1 templates in $M$. salemaai were achieved with $\lambda_{\max }\left(P_{\text {LWS }}\right) \approx 560 \mathrm{~nm}$ and $\lambda_{\max }\left(P_{\mathrm{MWS}}\right) \approx 515 \mathrm{~nm}$, whilst $M$. segerstralei was close 
Fig. 7 Theoretical performance of rhodopsins as function of their $\lambda_{\max }$ at two depths in the habitats of the main model population pair $L_{\mathrm{p}}$ (Lake Pääjärvi, $\# 10$ in Fig. 1; Table 1) and $S_{\mathrm{p}}$ (Pojoviken Bay, \#11). The thin dotted lines show the recorded illumination spectra (photons $\mathrm{m}^{-2} \mathrm{~s}^{-1} \mathrm{~nm}^{-1}$ ); for these the abscissa is light wavelength $\lambda$ (nm). The full-drawn curves show relative quantum catch (photon absorptions s ${ }^{-1}$ ) as function of the pigment's $\lambda_{\max }$. The dashed lines in the bottom panels show the conceptual signal-to-noise ratio $\left(\mathrm{SNR}_{\text {dark }}\right)$ of pigments as functions of $\lambda_{\max }$. All curves have been normalized to unity. The gray vertical bars mark the mean $\lambda_{\max }$ values actually recorded in the respective populations (Table 1)
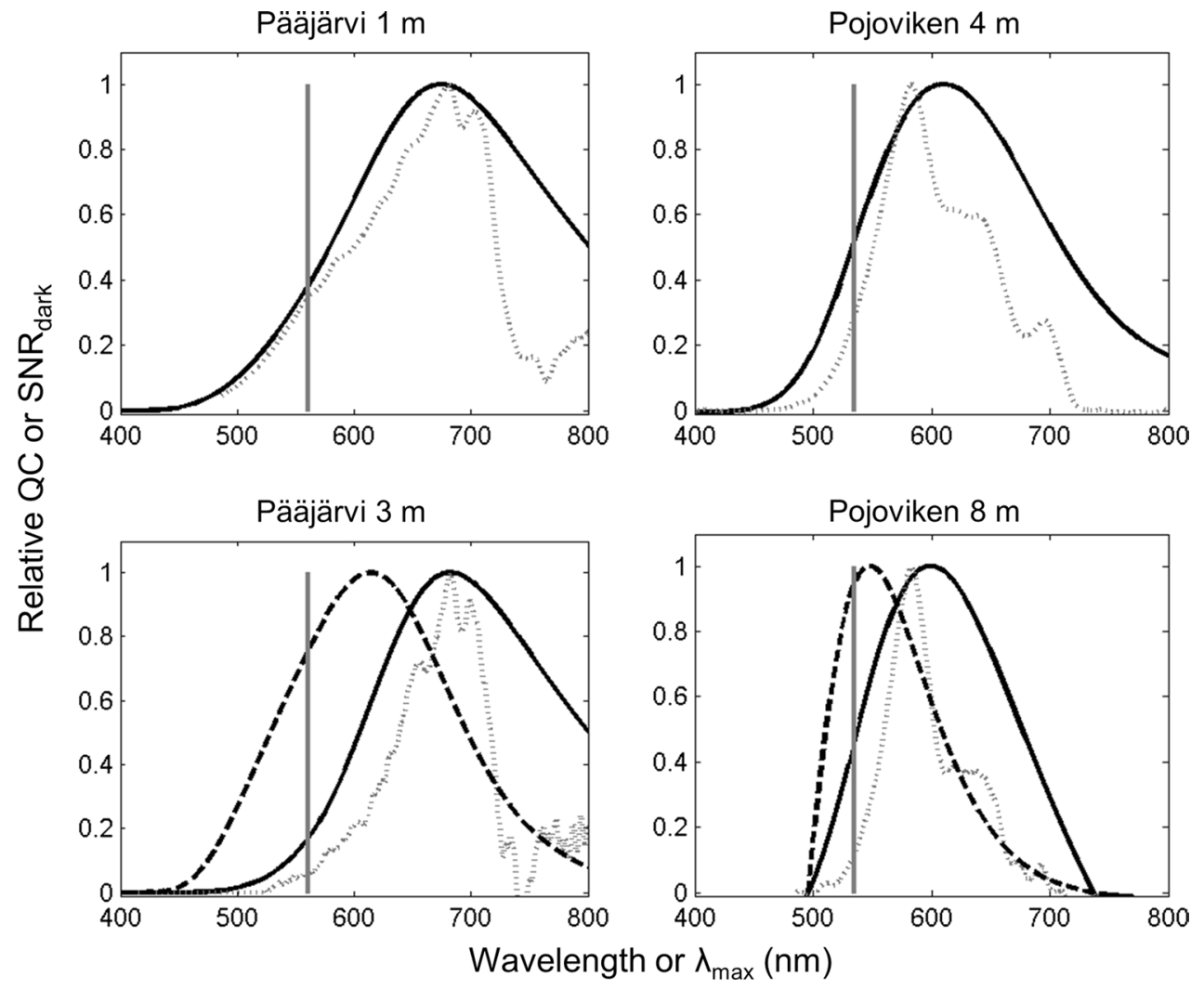

to $M$. relicta. It is worth emphasizing again, however, how emphatically the dichotomy of the $\lambda_{\max }$ distribution between the $L$ and $S$ groups overrides the inter-species variation of single-rhabdom absorbance spectra within the $L$ and $S$ groups.

\section{Hypothesis: a developmental reaction norm conserved from a common ancestor}

The summed evidence is consistent with the hypothesis that the expression of LWS and MWS opsins is subject to phenotypic plasticity controlled by some environmental factor(s) other than light that generally differ(s) between the brackish- and fresh-water habitats. This could be anything from salinity per se to, e.g., concentrations of specific ions $\left(\mathrm{Ca}^{2+}, \mathrm{Cl}^{-}\right)$, humic acids, or $\mathrm{pH}$. Light may play some role, but is clearly not the decisive factor. Resolving these questions requires further study.

The functionality of pigments with different $\lambda_{\max }$ for dim-light vision in a particular spectral environment can be measured either by quantum catch (QC) or by the conceptual signal-to-noise ratio $\left(\mathrm{SNR}_{\text {dark }}\right)$ of the pigment (Jokela-Määttä et al. 2007; Saarinen et al. 2012; see "Materials and methods"). QC is decisive at (somewhat) higher light levels, where the random arrival of photons ("quantal fluctuations") is a more powerful noise source than the spontaneous thermal activations of pigment molecules. At the very lowest light levels (near the absolute visual sensitivity limit), the decisive factor is $\mathrm{SNR}_{\text {dark }}$, calculated as $\mathrm{QC} / \sqrt{ }$ (thermal activations), where both $\mathrm{QC}$ and thermal activations are numbers of pigment activations per integration time (see "Materials and methods"). When plotted for a given photic environment as functions of pigment $\lambda_{\max }$, $\mathrm{SNR}_{\text {dark }}$ will peak at lower $\lambda_{\text {max }}$ values than QC, because the thermal activation rates of visual pigments increase with increasing $\lambda_{\max }$ (Barlow 1957; Ala-Laurila et al. 2004; Luo et al. 2011).

Figure 7 shows QC (bold full-drawn curves in all panels) and $\mathrm{SNR}_{\text {dark }}$ (bold dashed curves in bottom panels) as functions of pigment $\lambda_{\max }$ calculated for two depths in the habitats of our two main model populations $L_{\mathrm{p}}$ and $S_{\mathrm{p}}$. The actual light spectra are shown as thin dotted curves. The first observation is that both L- and S-type $\lambda_{\max }$ (here, 561 and $535 \mathrm{~nm}$, marked by vertical gray lines) fall far below that which would maximize QC in both light environments (here ca. 680 and $600 \mathrm{~nm}$, respectively). This changes little with depth. In the deeper layers, however, $\mathrm{SNR}_{\text {dark }}$ may become more relevant than QC as such, especially at twilight or night. The $\mathrm{SNR}_{\text {dark }}$ curves in the bottom panels show that the optimal $\lambda_{\max }$ is significantly shifted towards shorter wavelengths. Measured by $\mathrm{SNR}_{\text {dark }}$ deep in the Pojoviken environment, the spectral sensitivity of $S_{\mathrm{p}}$ is 
nearly optimal (only slightly on the "green" side of the optimum), but neither is the $\lambda_{\max }$ of $L_{\mathrm{p}}$ far from the Pojoviken optimum (only slightly on the "red" side). From the viewpoint of conceptual signal-to-noise ratio (absolute visual sensitivity), both S-type and L-type spectra would work quite well in the Baltic Sea, whereas the performance of S-type pigments would be considerably less good in Lake Pääjärvi.

Thus a possible evolutionary scenario might be as follows. The mysids that colonized coastal and continental waters during the Pleistocene experienced repeated and partly correlated changes in chemical conditions and water color when lakes and brackish inland seas were alternately sequestered and rejoined, even to the ocean, as the land sank and rose. The mysids, a primarily marine clade, have never had the A1 $\leftrightarrow$ A2 system for spectral tuning. Instead, they recruited a pre-existing dichromatic system, common in crustaceans (Wald 1968), for a similar purpose. The simple rule that "marine or brackish-water" conditions enhance expression of the shorter wavelength pigment and "freshwater" conditions expression of the longer wavelength pigment may then have been, on average, a useful predictive adaptation to photic conditions, in spite of random but less frequent deviations in specific cases. Going by default for long-wavelength sensitivity in fresh water will give a great advantage if the lake is brown, but no great disadvantage if the lake happens to have Baltic-like transmission. On the other hand, in the Baltic Sea truly "brownified" environments are never encountered and shorter wavelength sensitivity works better (Fig. 7). This predictive pattern would have been genetically fixed as a reaction norm (Woltereck 1909, 1928), against which there would seem to be no significant selection pressure. It mimicks the A1 $\leftrightarrow$ A2 system without incurring the excessive noisiness of A2 pigments (Donner et al. 1990; Ala-Laurila et al. 2007), which in terms of $\mathrm{SNR}_{\text {dark }}$ will easily offset or even reverse gains accruing from higher QC (cf. Saarinen et al. 2012). Most mysids live at least certain phases of their lives in very dim light, and need high absolute visual sensitivity (high $\mathrm{SNR}_{\text {dark }}$ ).

We should like to add two comments. First, the ERG experiments with polarized light (Fig. 6) indicated that LWS and MWS pigments are largely or wholly segregated into different cells with different properties. This suggests that the developmental switch controls not only the relative expression levels of the two pigments, but alternative pathways in photoreceptor development, involving both the pigments and the morphology and architecture of retinula cells. Second, the notion of an ancestral reaction norm generally conserved across species and populations does not exclude the possibility that some populations may have been fixed in either the $\mathrm{L}$ or the $\mathrm{S}$ state due to loss of function, e.g., in connection with population bottlenecks.

\section{Dichromatic vision and polarization sensitivity}

Differences in light polarization constitute a potentially useful source of visual information even in deep aquatic environments (Cronin and Shashar 2001; Cronin 2006). Polarization sensitivity may be used for orientation, both vertical and horizontal, for detecting food (breaking transparency camouflage) as well as for signaling (Shashar et al. 2004). The degrees and patterns of polarization are fairly constant over the wavelength range 400-580 nm down to considerable depths in the water $(\geq 15 \mathrm{~m}$ : Cronin and Shashar 2001). Mysids are known to use their vision at least for feeding and for assessment of depth in the water column, e.g., in connection with diel vertical migrations (Boscarino et al. 2009). Both tasks may benefit from polarization sensitivity.

The polarization-selectivity of $M$. relicta appeared to be mediated primarily by the minority-pigment cells in the respective population, i.e., MWS cells in $L_{\mathrm{p}}$ and LWS cells in $S_{\mathrm{p}}$ (Fig. 6). It is prima facie paradoxical that the potential for discrimination of wavelength and polarization should be coupled in the same cells. Obviously, the animal cannot then know whether a perceived contrast is due to a difference in color or polarization. Functionally, this suggests that disambiguation of wavelength and polarization contrasts has not been important, but that both serve the same tasks, be it prey detection or depth judgment (cf. Cronin 2006). Mechanistically, it supports the notion that pigment expression and cell morphology are under the control of the same developmental switch.

\section{Why have previous studies concluded that species of the Mysis relicta group possess only one opsin?}

The experiments with spectrally selective bleaching provide direct evidence for the presence of two visual pigments in the rhabdoms. Thus it is puzzling why DNA studies have failed to pick up more than one opsin gene in these populations. We wish to suggest the possibility that the genetic data may have been misinterpreted. Audzijonyte et al. (2012) did find two deeply diverged opsin lineages ("haplotypes" or "alleles") I and II, in their set of 35 populations representing all four glacial-relict species (cf. Table 1). They give several reasons for thinking that these are alleles of the same locus rather than, e.g., results of gene duplication, but none of them seems to be ultimately compelling. We tentatively suggest that the two "haplotypes" may in fact represent two opsin genes present and expressed in all the populations included here, although for unknown reasons differentially and seemingly randomly amplified in the DNA studies. In the study of Audzijonyte et al. (2012) most populations seemed to possess just one of these, but the genetic I/II dichotomy does not correlate 
with the phenotypic $S / L$ dichotomy (see Table 1$)$. In only two of the populations included here (M. salemaai from "sea" localities \#3 and \#4 in Fig. 1b) both haplotypes were found, but interestingly, these populations have pure S-type absorbance spectra and low inter-individual variability (population mean $\pm \operatorname{SEM} \lambda_{\max }=521.2 \pm 0.4$ and $525.4 \pm 0.3 \mathrm{~nm}$ ), with no suggestion of either intermediate $\lambda_{\max }$ values or increased polymorphism.

We further note that the deep divergence of haplotypes I and II, estimated to have occurred before the speciation events, would be consistent with our hypothesis of two pigments present in all species but differentially expressed according to a conserved reaction norm. The idea of two opsin genes could also resolve some of the paradoxes encountered in the comparison of mtDNA phylogeny with opsin gene phylogeny under the single-opsin-gene assumption (Audzijonyte et al. 2012).

\section{Mysis diluviana}

The fourth of the glacial-relict Mysis sibling species, the North American M. diluviana, ought to be reinvestigated in light of the present results. Jokela-Määttä et al. (2005) reported a wide variation range $(495-529 \mathrm{~nm})$ of singlerhabdom $\lambda_{\max }$ measured in four individuals from two lakes in Idaho, USA (Hayden Lake and Pend Oreille). Cronin (2006) has published two within-individual average spectra, also from Idaho $M$. diluviana, one well-fitted by a $505 \mathrm{~nm} \mathrm{~A} 1$ template, the other by a $517 \mathrm{~nm} \mathrm{~A} 2$ template. The common interpretation at the time was that this species uses $\mathrm{A} 1 \leftrightarrow \mathrm{A} 2$ chromophore exchange. Yet, as Cronin (2006) notes, the A2 pair of an A1 pigment peaking at $505 \mathrm{~nm}$ should have $\lambda_{\max }=535 \mathrm{~nm}$, so the broad $517 \mathrm{~nm}$ spectrum would have arisen from a mixture. In fact, it is quite similar to the spectra we have here obtained from the marine $M$. mixta $\left(\lambda_{\max }=517-525 \mathrm{~nm}\right.$; Table 1). Gal et al. (1999) reported an A1 pigment in M. diluviana from Cayuga Lake (NY, USA) with $\lambda_{\max }$ at $520 \mathrm{~nm}$, and together with the $505 \mathrm{~nm}$ pigment, this might obviously produce a $517 \mathrm{~nm} \mathrm{~A} 1 / \mathrm{A} 1$ mixture.

As argued above, it seems unlikely that $M$. diluviana should have an A1 $\leftrightarrow$ A2 system that is absent in M. relicta. Rather, the variation of spectral sensitivity in M. diluviana might indicate differences in how the expression of the two opsins is regulated. It is interesting that both Cronin (2006) and Gal et al. (1999) were able to record seemingly pure A1 spectra from whole rhabdoms, suggesting that $M$. diluviana expresses either of its two opsins alone at least in some rhabdoms. Obviously, it can also express mixtures, as shown by Cronin's $517 \mathrm{~nm}$ spectrum and by the wide spectral variation reported by Jokela-Määttä et al. (2005). Detailed study of $M$. diluviana as a sibling species of M. relicta, M. salemaai and M. segerstralei would be of special interest quite irrespective of the large-scale opportunities offered by the wider genus Mysis.

Acknowledgments This research formed part of a long-term collaborative project (Project 10) of the Academy of Finland and the Russian Academy of Sciences. The lasting support of the two Academies is gratefully acknowledged, as well as additional funding from Program 7 of the Presidium of the Russian Academy of Sciences and a Grant of the President of the Russian Federation for leading scientific schools. The present study has been supported by grants from Societas Scientiarum Fennica, The Ella and Georg Ehrnrooth Foundation, Societas pro Fauna et Flora Fennica, and Häme Student Foundation. We wish to acknowledge the initial collaboration initiative of the late Professor Kai Otto Donner as President of the Academy of Finland, and the early contributions of the late Dr Irina Fedorovich. We thank Drs Tom Reuter, Victor Govardovskii and Petri Ala-Laurila for illuminating discussions and technical help over many years, Dr Risto Väinölä for determining the species of some of our mysids, and the doctoral students who participated in earlier studies: Drs Johan Pahlberg, Mirka Jokela-Määttä, Julia Demchuk, Amna Abu Khamidakh, Marina Yakovleva and Nikolai Belikov. Thanks are due also to the staff of Tvärminne Zoological Station for constant technical support, as well as to Lammi Biological Station and to Ms Noora Nevala and Maiju Lehtiniemi for field assistance.

Open Access This article is distributed under the terms of the Creative Commons Attribution 4.0 International License (http://creativecommons.org/licenses/by/4.0/), which permits unrestricted use, distribution, and reproduction in any medium, provided you give appropriate credit to the original author(s) and the source, provide a link to the Creative Commons license, and indicate if changes were made.

\section{References}

Ala-Laurila P, Donner K, Koskelainen A (2004) Thermal activation and photoactivation of visual pigments. Biophys J 86:3653-3662

Ala-Laurila P, Donner K, Crouch RK, Cornwall MC (2007) Chromophore switch from 11-cis-dehydroretinal (A2) to 11-cis-retinal (A1) decreases dark noise in salamander red rods. J Physiol 585:57-74

Audzijonyte A, Väinölä R (2005) Diversity and distribution of circumpolar fresh- and brackish-water Mysis (Crustacea: Mysida): description of $M$. relicta Lovén, 1862, M. salemaai $\mathrm{n}$. sp., $M$. segerstralei $\mathrm{n}$. sp. and $M$. diluviana $\mathrm{n}$. sp., based on molecular and morphological characters. Hydrobiologia 544:89-141

Audzijonyte A, Väinölä R (2006) Phylogeographic analyses of a circumarctic coastal and a boreal lacustrine mysid crustacean, and evidence of fast postglacial mtDNA rates. Mol Ecol 15:3287-3301

Audzijonyte A, Damgaard J, Varvio S-L, Vainio JK, Väinölä R (2005) Phylogeny of Mysis (Crustacea, Mysida): history of continental invasions inferred from molecular and morphological data. Cladistics 21:575-596

Audzijonyte A, Pahlberg J, Viljanen M, Donner K, Väinölä R (2012) Opsin gene sequence variation across phylogenetic and population histories in Mysis (Crustacea: Mysida) does not match current light environments or visual-pigment absorbance spectra. Mol Ecol 21:2176-2196

Barlow HB (1957) Purkinje shift and retinal noise. Nature 179:255

Belikov N, Yakovleva M, Feldman T, Demina O, Khodonov A, Lindström M, Donner K, Ostrovsky M (2014) Lake and sea 
populations of Mysis relicta (Crustacea, Mysida) with different visual-pigment absorbance spectra use the same A1 chromophore. PLoS One 9(2):e88107. doi:10.1371/journal. pone.0088107

Boscarino BT, Rudstam LG, Loew ER, Mills EL (2009) Predicting the vertical distribution of the opossum shrimp, Mysis relicta, in Lake Ontario: a test of laboratory-based light preferences. Can J Fish Aquat Sci 66:101-113

Bridges CDB (1972) The rhodopsin-porphyropsin visual system. In: Dartnall HJA (ed) Handbook of sensory physiology VII/1: photochemistry of vision. Springer, Berlin, pp 417-480

Cronin TW (2006) Invertebrate vision in water. In: Warrant E, Nilsson D-E (eds) Invertebrate vision. Cambridge University Press, Cambridge, pp 211-249

Cronin TW, Shashar N (2001) The linearly polarized light field in clear, tropical marine waters: spatial and temporal variation of light intensity, degree of polarization and e-vector angle. J Exp Biol 204:2461-2467

Dartnall HAJ, Lythgoe JN (1965) The spectral clustering of visual pigments. Vis Res 5:81-100

Donner K, Firsov ML, Govardovskii VI (1990) The frequency of isomerization-like 'dark' events in rhodopsin and porphyropsin rods of the bull-frog retina. J Physiol 428:673-692

Donner K, Hemilä S, Koskelainen A (1992) On the relation between ERG waves and retinal function: inverted rod photoresponses from the frog retina. Vis Res 32:1411-1416

Enright JM, Toomey MB, Sato S, Temple SE, Allen JR, Fujiwara R, Kramlinger VM, Nagy LD, Johnson KM, Xiao Y, How MJ, Johnson SL, Roberts NW, Kefalov VJ, Guengerich FP, Corbo JC (2015) Cyp27c1 red-shifts the spectral sensitivity of photoreceptors by converting vitamin $\mathrm{A}_{1}$ into $\mathrm{A}_{2}$. Curr Biol 25:3048-3057

Eronen M, Gluckert G, Hatakka L, van der Plassche O, van der Plicht J, Rantala P (2001) Rates of Holocene isostatic uplift and relative sea-level lowering of the Baltic in SW Finland based on studies of isolation contacts. Boreas 30:17-30

Fein A, Szuts EZ (1982) Photoreceptors: their role in vision. IUPAB biophysics series 5. Cambridge University Press, Cambridge

Gal G, Loew ER, Rudstam LG, Mohammadian AM (1999) Light and diel vertical migration: spectral sensitivity and light avoidance by Mysis relicta. Can J Fish Aquat Sci 56:311-322

Govardovskii VI, Fyhrquist N, Reuter T, Kuzmin DG, Donner K (2000) In search of the visual pigment template. Visual Neurosci 17:509-528

Hárosi FI (1994) An analysis of two spectral properties of vertebrate visual pigments. Vis Res 34:1359-1367

Jokela-Määttä M, Pahlberg J, Lindström M, Porter M, Zak P, Ostrovsky M, Cronin T, Donner K (2005) Visual pigment absorbance spectra and spectral sensitivity of Mysis relicta (Crustacea, Mysida) in different light environments. J Comp Physiol A 191:1087-1097

Jokela-Määttä M, Smura T, Aaltonen A, Ala-Laurila P, Donner K (2007) Visual pigments of Baltic Sea fishes of marine and limnic origin. Visual Neurosci 24:389-398

Lindström M (2000) Eye function of Mysidacea (Crustacea) in the northern Baltic Sea. J Exp Mar Biol Ecol 246:85-101

Lindström M, Nilsson HL (1988) Eye function of Mysis relicta Lovén (Crustacea) from two photic environments. Spectral sensitivity and light tolerance. J Exp Mar Biol Ecol 120:23-37
Luo D-G, Yue WWS, Ala-Laurila P, Yau K-W (2011) Activation of visual pigments by light and heat. Science 332:1307-1312

Pahlberg J, Lindström M, Ala-Laurila P, Fyhrquist-Vanni N, Koskelainen A, Donner K (2005) The photoactivation energy of the visual pigment in two spectrally different populations of Mysis relicta (Crustacea, Mysida). J Comp Physiol A 191:837-844

Saarinen P, Pahlberg J, Herczeg G, Viljanen M, Karjalainen M, Shikano T, Merilä J, Donner K (2012) Spectral tuning by selective chromophore uptake in rods and cones of eight populations of nine-spined stickleback (Pungitius pungitius). J Exp Biol 215:2760-2773

Schwanzara SA (1967) The visual pigments of freshwater fishes. Vis Res 7:121-148

Shashar N, Sabbah S, Cronin TW (2004) Transmission of linearly polarized light in seawater: implications for polarization signaling. J Exp Biol 207:3619-3628

Stiles WS (1949) Investigations of the scotopic and trichromatic mechanisms of vision by the two-colour threshold technique. Rev Opt 28:215-237

Suzuki T, Makino-Tasaka M, Eguchi E (1984) 3-Dehydroretinal (vitamin A2 aldehyde) in crayfish eye. Vis Res 24:783-787

Suzuki T, Arigawa K, Eguchi E (1985) The effects of light and temperature on the rhodopsin-porphyropsin visual system of the crayfish Procambarus clarkii. Zool Sci 2:455-461

Suzuki T, Terakita A, Tsin ATC (1993) Retinoid metabolism and conversion of retinol to dehydroretinol in the crayfish (Procambarus clarkii) retina. Comp Biochem Physiol 105B:257-261

Temple SE, Plate EM, Ramsden S, Haimberger TJ, Roth WM, Hawryshyn CW (2006) Seasonal cycle in vitamin A1/A2-Based visual pigment composition during the life history of coho salmon (Oncorhynchus Kisutch). J Comp Physiol A 192:301-313

Väinölä R (1986) Sibling species and phylogenetic relationships of Mysis relicta (Crustacea: Mysidacea). Ann Zool Fenn 23:207-221

Väinölä R, Riddoch BJ, Ward RD, Jones RI (1994) Genetic zoogeography of the Mysis relicta species group (Crustacea: Mysidacea) in northern Europe and North America. Can J Fish Aquat Sci 51:1490-1505

Väinölä R, Audzijonyte A, Riddoch BJ (2002) Morphometric discrimination among four species of the Mysis relicta group. Arch Hydrobiol 155:493-515

Wald G (1968) Single and multiple visual systems in arthropods. J Gen Physiol 51:125-155

Woltereck R (1909) Weitere experimentelle Untersuchungen über Artveränderung, speziell über das Wesen quantitativer Artunterschiede bei Daphniden. Verh Dtsch Zool Ges 19:110-173

Woltereck R (1928) Bemerkungen über die Begriffe "Reaktionsnorm" und "Klon". Biol Zent Bl 48:167-172

Zak PP, Demchuk JV, Abu Khamidakh AE, Trofimova NN, Ostrovsky M (2009) Identification of crustacean visual pigment chromophores by microspectrophotometric measurements. Sens Sist 23:318-324 (in Russian)

Zak PP, Lindström M, Demchuk JV, Donner K, Ostrovsky M (2013) The eye of the opossum shrimp Mysis relicta (Crustacea, Mysidae) contains two visual pigments located in different photoreceptor cells. Dokl Biol Sci 449:68-72 